\title{
Na Pista e no Morro com o Balanço do Jamelão
}

* Recebido em: 02.08.2018. Aprovado em: 20.11.2018

${ }^{1}$ Graduada em Psicologia, a fotografia invadiu minha vida durante o terceiro ano de faculdade. Um desvio de percurso me levou a experimentar cerâmica (por um curto período) e gravura (por um período mais longo), o que resultou em uma exposição individual. Outras exposições coletivas vieram, tanto com gravura quanto con folográm, fin Pho Web Alianc Frana na Prix Photo Web Aliança Francesa de 2014, no $7^{\circ}$ Euroclick em 2015 e no Observations Street Photography Festival na Alemanhã em 2017. Sou membro do Flanares - um coletivo de fotógrafos brasileiros dedicado a fotografia de rua, do Negras[fotos]grafias - coletivo de fotógrafas negras e do Mamana - coletivo de mulheres fóna - coletivo de mulheres fotógrafas.
https://www.tetesilva.com/; tete.silva@gmail.com
On the Track and on the Hill with the Jamelão Balance

Tetê Silva

Resumo - Este ensaio fotográfico é um encontro com o bloco Balanço do Jamelão, do Andaraí, Zona Norte do Rio de Janeiro. As fotografias foram realizadas entre 2012 e 2015, e depois em 2018, em um reencontro com os amigos do bloco e da comunidade. Aqui presente também está uma entrevista feita com dois componentes do bloco, Waltencir Bastos de Souza (o Lilico), presidente do bloco, e Reinaldo Dias da Silva, diretor de comunicação. Aqui, a saída do bloco, os desafios e desejos de brincar e agregar os moradores do Morro do Jamelão se faz presente no corpo dos foliões, moradores, vizinhos e amigos de todas as idades.
Abstract - This photographic essay is an encounter with the carnival block Balanço do Jamelão, from Andaraí, Northern Zone of Rio de Janeiro. The photos were taken between 2012 and 2015, and then in 2018, in a reunion with the friends of the block and the community. It is also an interview with two components, Waltencir Bastos de Souza (Lilico), president of the group, and Reinaldo Dias da Silva, communication director. Here, the parade of the carnival block, the challenges and desires to play and to involve the habitants of Morro do Jamelão is present in the body of revelers, residents, neighbors and friends of all ages. 
${ }^{1}$ Bairro do Grajaú, divisa com Andaraí.

${ }^{2} \mathrm{O}$ Encontro São Paulo/Rio é o maior evento do Morro do Jamelão. Trata-se de um intercâmbio de samba e futebol entre o morro carioca e a comunidade de Xurupita, no Jaraguá, capital paulista. O evento dura dois dias (no Rio de Janeiro cai sempre no dia 20 de janeiro, em São Paulo acontece em setembro), já tendo ocorrido a terceira edição com a vinda de ocorrido a terceira edição com a vinda de
60 pessoas de São Paulo. Surgiu quando um morador do morro, Carlos Silva, mudou-se para São Paulo, onde travou contato com moradores de Xurupita.
Fotografei o bloco Balanço do Jamelão de 2012 a 2015. Depois interrompi. Não sei bem porque, como também não sei o motivo que me fez querer voltar a fotografá-lo em 2018. Saudade, curiosidade pelo que estava acontecendo, vontade de retornar à tradicional feijoada que a agremiação oferece no Morro do Jamelão, no bairro carioca do Andaraí. Revivi o carinho que sentia pela gente toda da comunidade, um bem-querer pelas pessoas que não se explica.

Ou se explica sim. O Balanço não é uma escola de samba, mas um bloco, no qual, em meio ao comprometimento que os componentes têm com o carnaval, ouço também a espontaneidade do folião. Não é um bloco famoso que arrasta multidões de cariocas e estrangeiros, felizes e anônimos. Ao contrário, eles são poucos, cada integrante tem um nome ou apelido conhecido pelo componente ao lado. Daí minha esperança de captar o momento único, mesmo irreal, quando o desfile de um pequeno bloco de comunidade se confunde com a conversa no portão de casa, com uma briga entre vizinhos, com o ajuste de contas com a vida cotidiana, com a felicidade de abraçar um amigo.

$\mathrm{Eu}$ quis pegar um pouco desse espírito numa conversa informal que tive com dois integrantes do Balanço: Waltencir Bastos de Souza (o Lilico), presidente do bloco, e Reinaldo Dias da Silva, diretor de comunicação. Gente que literalmente põe o bloco na rua, a despeito de todas as dificuldades e falta de apoio.

Quando foi fundado o Balanço do Jamelão?
Reinaldo: Em 2006 no Morro do Jamelão, mas tem participante de todo o Complexo do Andaraí, que também inclui Caçapava, Divineia, etc. Mas só começou a desfilar aqui embaixo em 2010, na esquina da rua Botucatu com rua Rosa e Silva ${ }^{1}$, antes era só lá no alto do morro.

Como é a relação com quem trabalha no bloco? Há alguma relação profissional?

Lilico: Olha, no momento não há possibilidade alguma de remuneração. Todo dinheiro arrecadado vai para o bloco que precisa de dinheiro, da manutenção dos instrumentos à água para os músicos. O que é feito é por amor, não pelo dinheiro. No geral, é com a ajuda dos amigos que tocamos o bloco, mais do que qualquer outra coisa.

Mas vocês não recebem nenhum apoio do Estado?

Reinaldo: Já tivemos apoio da subprefeitura. Mas atualmente o único apoio externo que recebemos é da AmBev porque somos membros da Associação de Bandas e Blocos da Grande Tijuca. A AmBev dá um determinado número de latinhas de cerveja para a Associação que compartilha com os blocos. A venda das latinhas ajuda a custear o nosso carnaval. Mas a maior fonte de renda vem é da venda de abadás, que custeia não só o desfile como os eventos que promovemos. Os principais são o desfile de carnaval, a feijoada e o Encontro São Paulo/Rio ${ }^{2}$. A gente também promove shows por demanda, para aumentar a renda, não só de samba, mas 
também de pagode. Há o desejo de legalizar o bloco criando um CNPJ, acho que facilitaria as coisas.

Além da falta de apoio, vocês enfrentam outras dificuldades?

Reinaldo: A maior dificuldade é trazer para os ensaios as pessoas que querem participar. Estamos aqui no alto, já teve tiroteio, inclusive durante um ensaio. É difícil porque quem está embaixo não pode subir, então perdemos um participante, mas também perdemos mais uma fonte de renda. Mas quem vive lá no alto também não quer descer de vez, é algo compreensível, mesmo que se traga o desfile também para o asfalto, não se pode deixar de fazer lá porque é a única forma de entretenimento das pessoas.

Qual o aspecto mais positivo do Balanço do Jamelão para o morro?

Lilico: É a parte social. Tentamos criar parcerias para organizar cursos, para fazer uma ação social no dia das crianças, no Natal, enfim, para trazer melhorias para as pessoas daqui que prossigam para além do Carnaval. É importante também por trazer a juventude para ações positivas e para que tenham uma relação melhor com os mais velhos.

Essa interação entre jovens e pessoas mais velhas sempre aconteceu no Balanço do Jamelão?

Reinaldo: Isso começou a ficar mais pronunciado a partir de 2010 quando começamos a descer para o asfalto, houve uma maior procura dos jovens para aprender a tocar instrumentos de percussão. Acho que foi a partir desse ponto que começou a surgir essa relação de aprendizagem entre as diferentes gerações. Tínhamos até um dia só para isso, a quinta-feira. No momento não está acontecendo, mas é a parte mais bacana do bloco.

Já houve algum momento complicado nestes anos de existência do bloco?

Lilico: O pior momento foi em 2013. Estávamos com tudo preparado para descer e desfilar quando teve uma invasão, o que acabou afastando muita gente do bloco.

Vocês guardam algum momento curioso ocorrido nos desfiles?

Lilico: Ah, o melhor momento foi em 2012. O enredo escolhido foi sobre o mosquito da dengue, foi dos anos mais engraçados. Inclusive, muita gente achou que o samba enredo deveria ter sido incluído na campanha contra a dengue. Seu Paulo, que a gente conhecia como Paulette, se fantasiou de mosquito e foi o folião mais fotografado daquele ano. Ele ficou todo orgulhoso. Até hoje a gente ri de tudo que aconteceu naquele desfile. No ano seguinte o enredo foi " 171 " e Paulette veio de terno, carregando uma mala com o número 171 grudado. A partir de então o pessoal começou a se perguntar como ele viria fantasiado. Infelizmente, Seu Paulo já faleceu e o enredo de 2016 foi em homenagem a ele.

O Balanço do Jamelão ainda é um bloco comunitário, não? 
Lilico: Acho que metade dos integrantes é composta por familiares. $\mathrm{O}$ atual diretor de bateria é da segunda geração e a neta dele já participa. A bateria e os compositores são o que há de mais importante no bloco. Os compositores são os responsáveis por desenvolver o enredo a cada ano. O meu pai [Walter do Jamelão] é um dos compositores, o Aranha [Sebastião Silva] também. Mas o que se diz é que os Marins e os Neves dominam todo o bloco. E é isso mesmo, quase toda família lá tem um dos dois sobrenomes [risos].

\section{Quais os desafios para o futuro?}

Lilico: Atualmente fazemos tudo na rua, seria importante construir a sede do bloco, ter um espaço para se reunir e desenvolver outras atividades. Por exemplo, temos um espaço onde acontece a feijoada, mas é aberto. Com relação aos cursos que pretendemos organizar, o espaço aberto dificulta. Qualquer coisa que aconteça na rua já tira a atenção, principalmente quando

se lida com crianças e adolescentes.

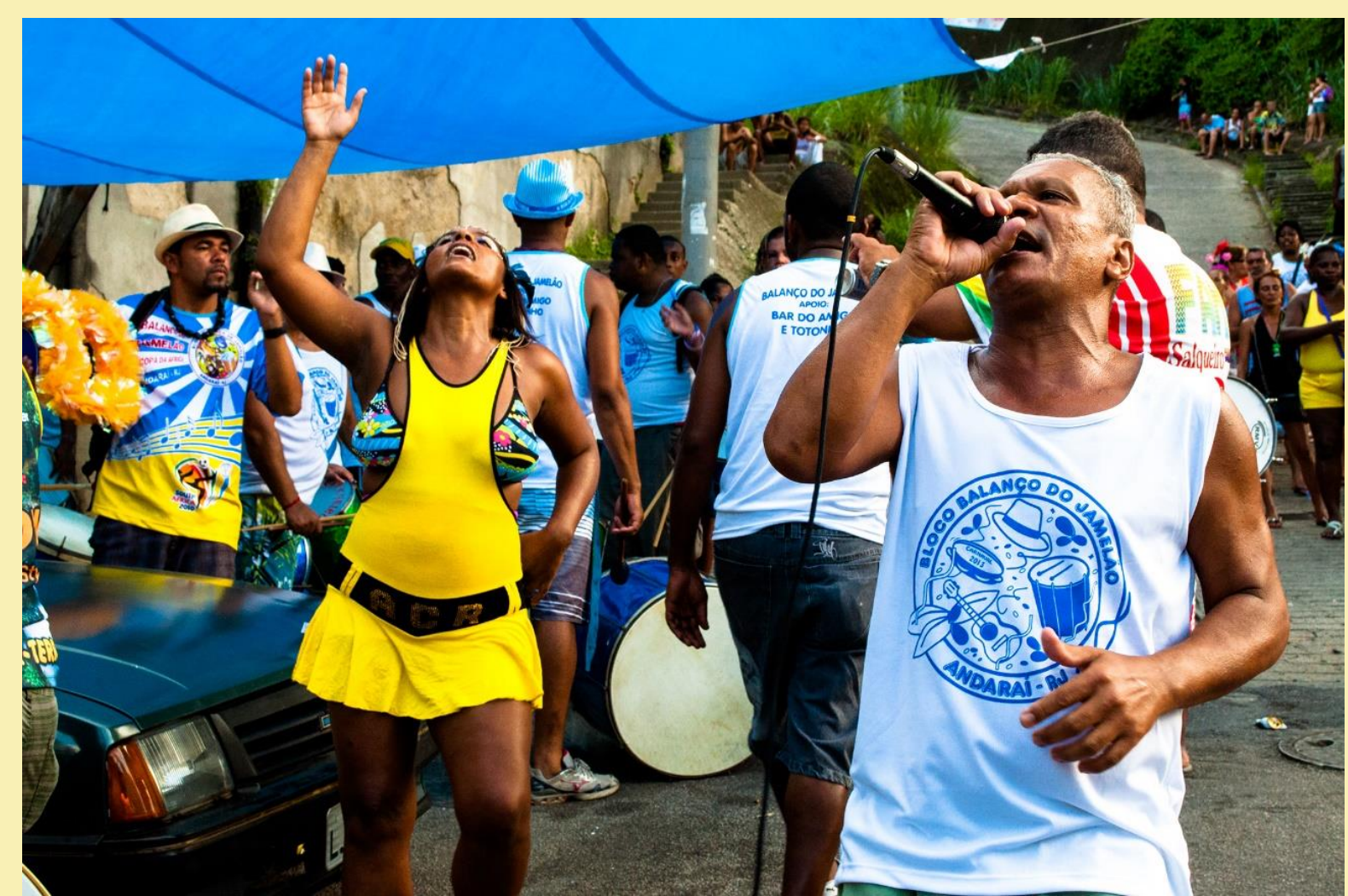



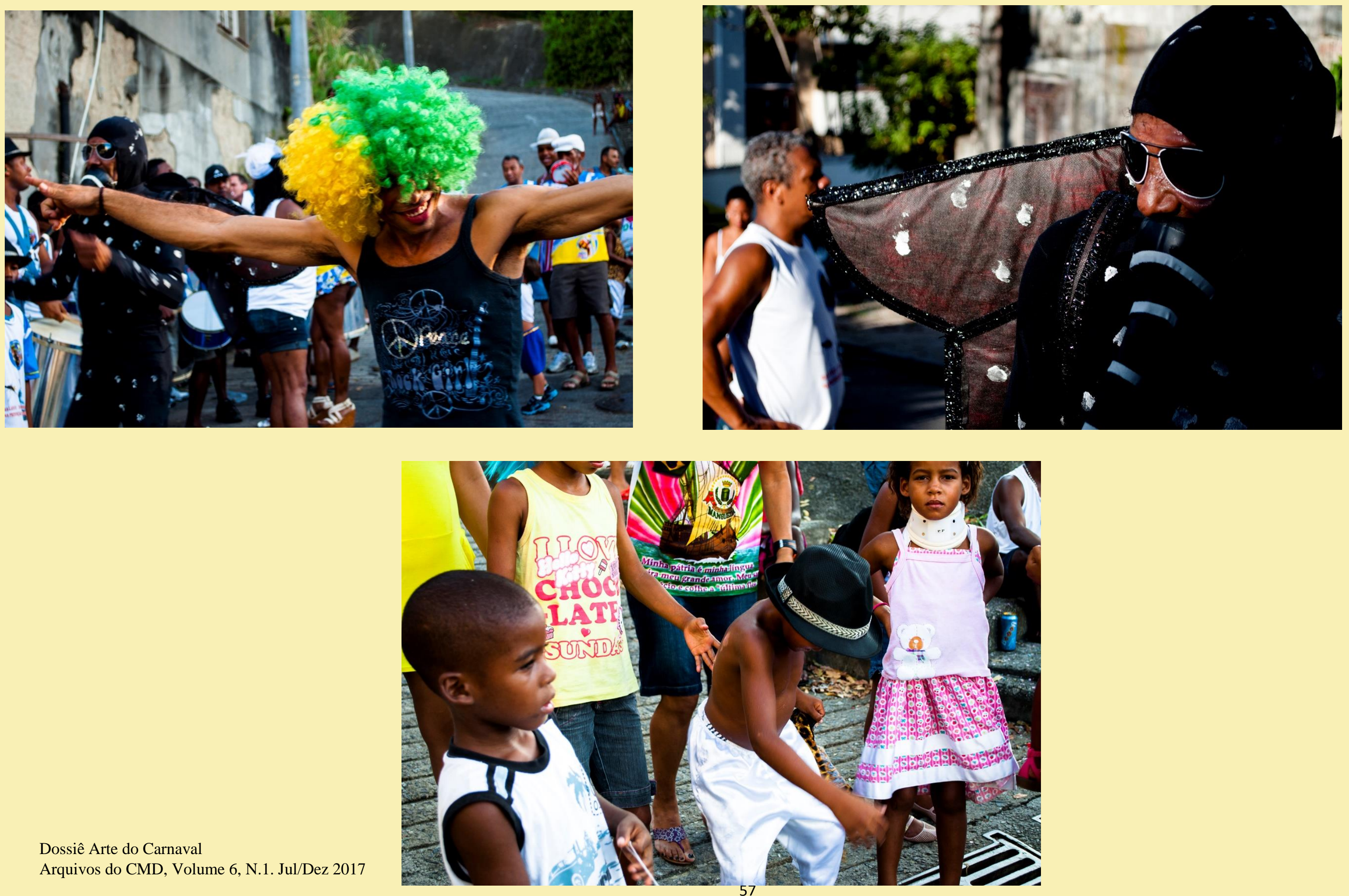

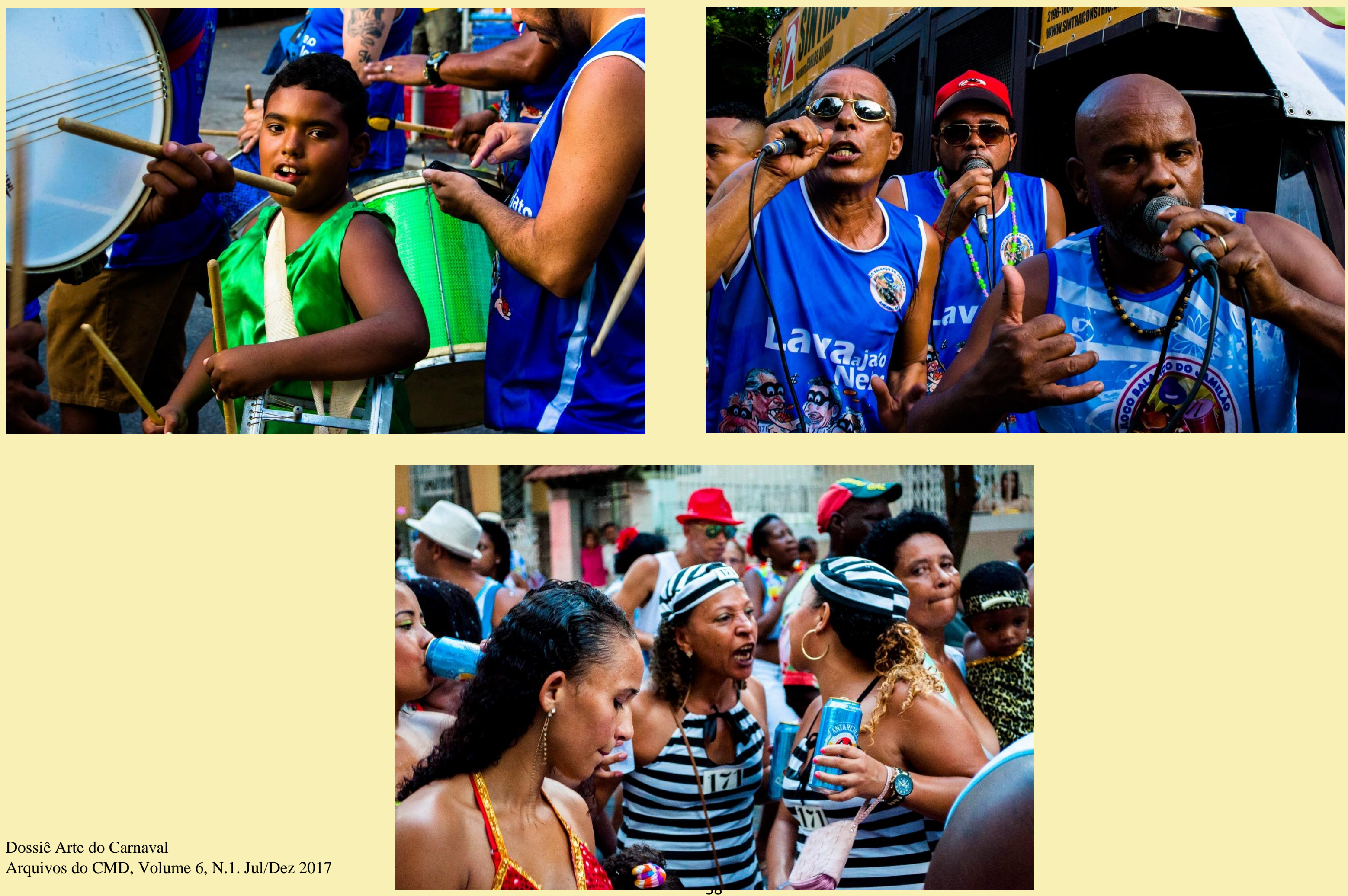

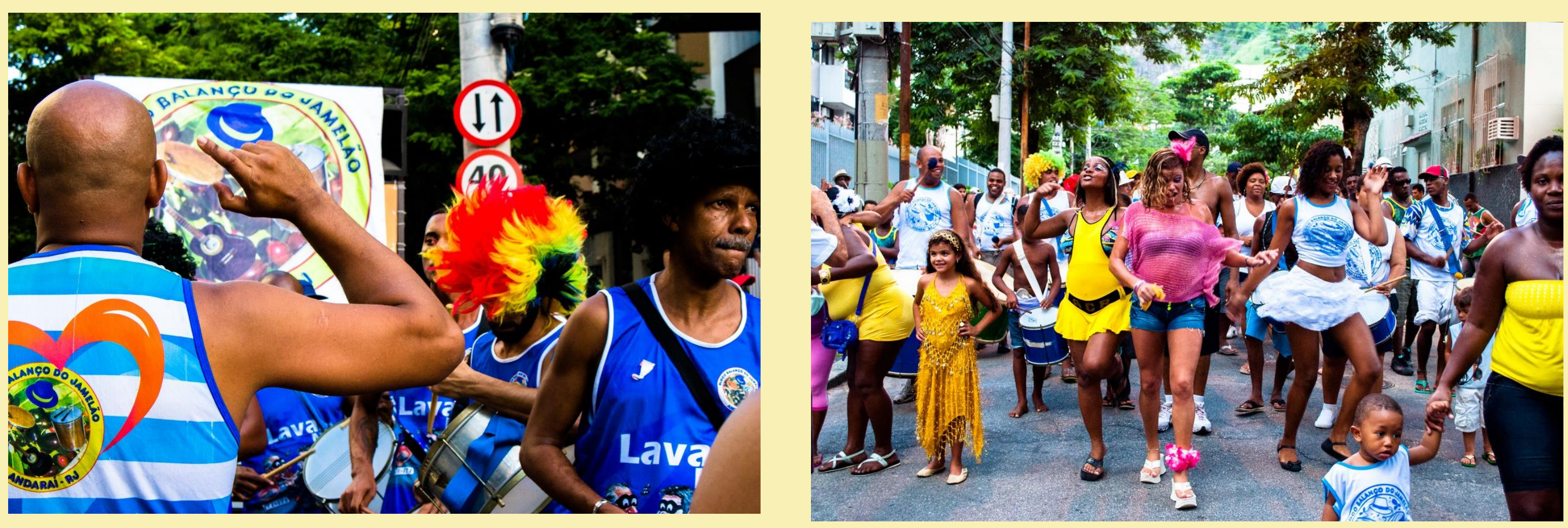

Dossiê Arte do Carnaval

Arquivos do CMD, Volume 6, N.1. Jul/Dez 2017

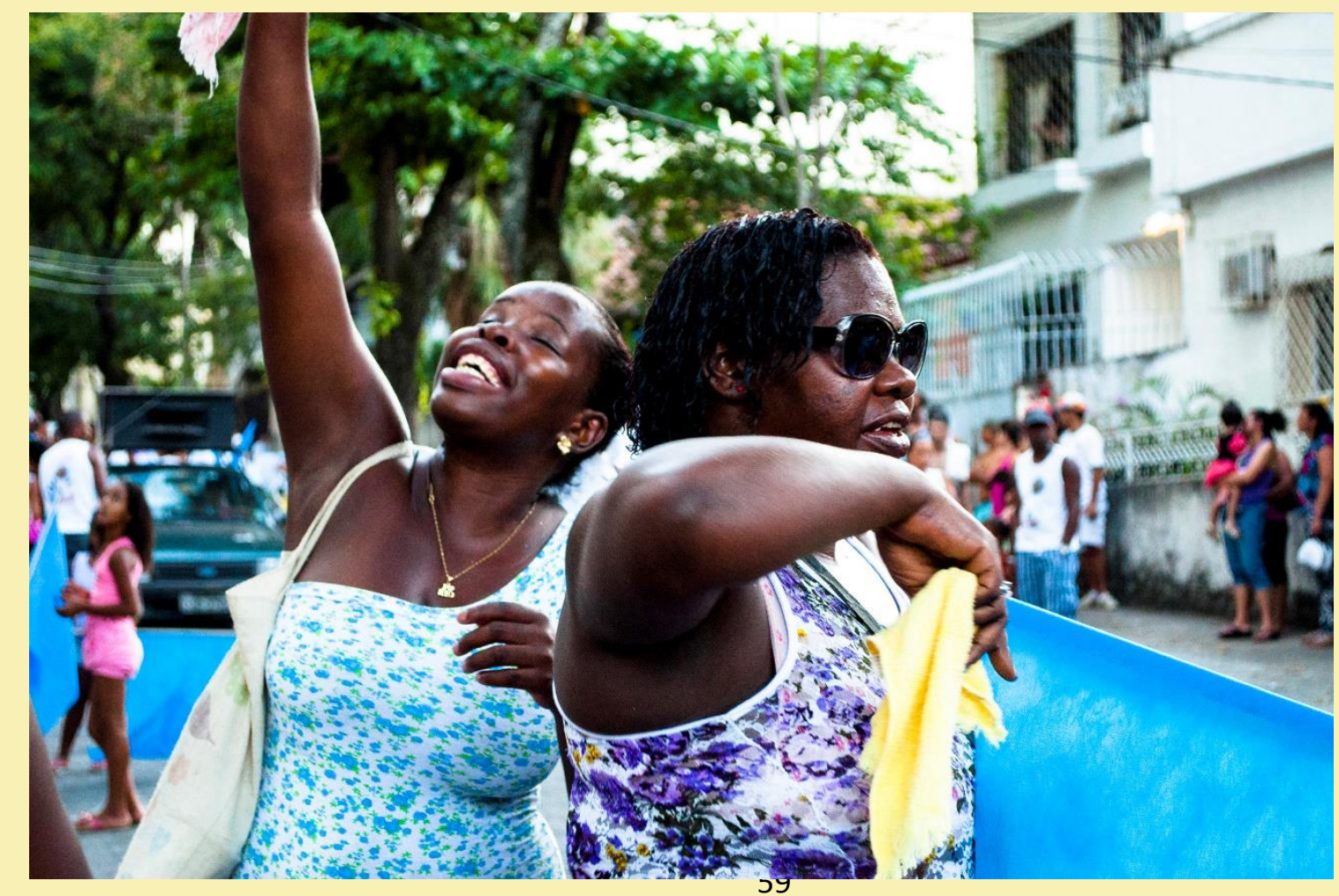



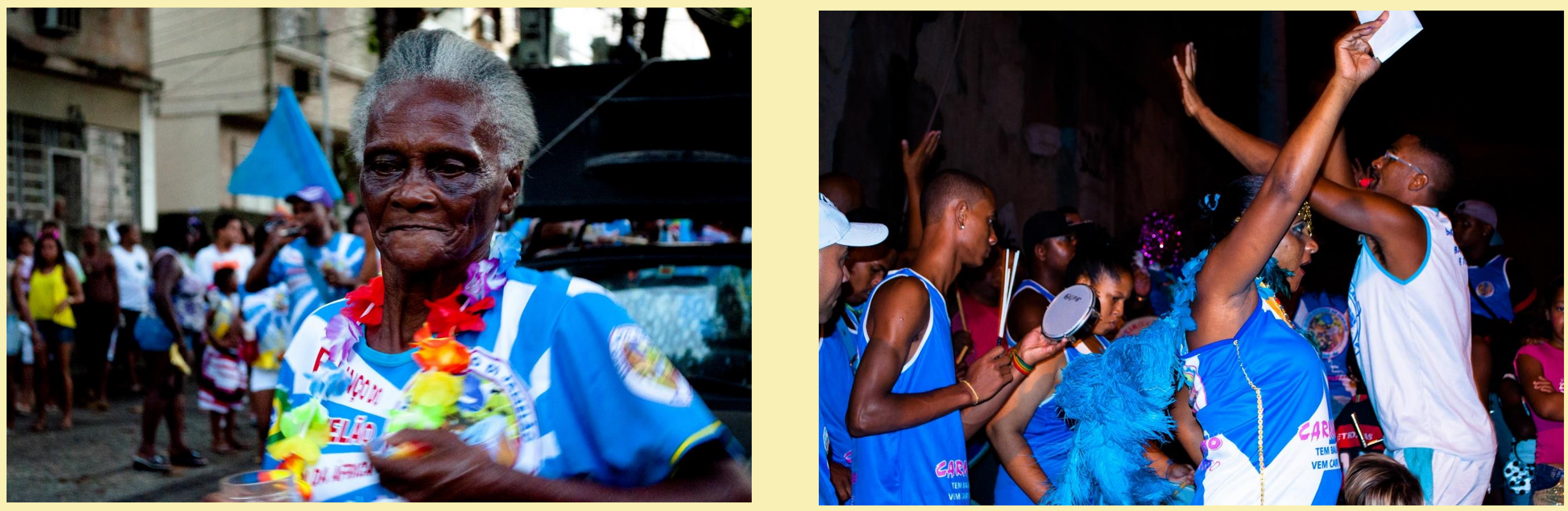